\title{
O ensino do Atletismo em ambiente escolar: limitações, abordagens e possiveis adaptações materiais
}

Athletics teaching in the school environment: limitations, approaches and possible material adaptations La enseñanza del Atletismo en entorno escolar: limitaciones, enfoques y posibles adaptaciones materiales

\author{
Lucas Matozo Milan \\ Universidade Estadual de Maringá, Brasil \\ lucas21milan.frjp@gmail.com
}

(DD https://orcid.org/0000-0001-7536-0519

\author{
Gabriel Martins del Borgo \\ Universidade Estadual de Maringá, Brasil \\ ra115234@uem.br \\ Dhttps://orcid.org/0000-0002-5144-0546
}

Jeferson Roberto Rojo

Universidade Estadual de Maringá, Brasil

jeferson.rojo@hotmail.com

(DD https://orcid.org/0000-0002-6291-6247

\begin{abstract}
Resumo:
Mesmo com uma produção acadêmica voltada a sua aplicação dentro da escola, os estudos apontam que o atletismo ainda é subutilizado. Nesse sentido, o presente estudo teve como objetivo analisar artigos relacionados ao ensino e as possíveis adaptações de materiais no atletismo escolar, assim como as problemáticas e aplicações desse conteúdo. Para isso, foi realizada uma revisão narrativa a partir de 25 fontes. Com a leitura das fontes, dividiu-se os temas em 3 categorias centrais: Limitações e Problemáticas no Ensino, Possibilidades no Ensino do Atletismo e Possíveis Adaptações Materiais. Por fim, concluiu-se que há questionamento dos autores sobre as limitações presentes nas escolas, assim como procuram entender e analisar porque as limitações se fazem presentes no âmbito escolar, contudo observou-se que o ensino do atletismo nas escolas pode ser realizado a partir de diferentes abordagens, além de que é possível realizar adaptações físicas e materiais para trabalhar com as provas do atletismo no contexto da Educação Física escolar.
\end{abstract}

PalaVras-ChaVe: Atletismo, Ensino escolar, Educação Física.

\section{ABSTRACT:}

Even with an academic production focused on its application within the school, studies show that athletics is still underutilized. In this sense, the present study aimed to analyze articles related to teaching and the possible adaptations of materials in school athletics, as well as the problems and applications of this content. For this, a narrative review was carried out from 25 sources. With the reading of the sources, the themes were divided into 3 central categories: Limitations and Problems in Teaching, Possibilities in the Teaching of Athletics and Possible Material Adaptations. Finally, it was concluded that there are questions from the authors about the limitations present in schools, as well as trying to understand and analyze why the limitations are present in the school environment, however it was observed that the teaching of athletics in schools can be carried out from different approaches, in addition to the fact that it is possible to make physical and material adaptations to work with athletics tests in the context of school Physical Education.

KEYwORDS: Athletic, Scholar Teaching, Physical Education. 


\section{Resumen:}

Incluso con una producción académica centrada en su aplicación dentro de la escuela, los estudios muestran que el atletismo todavía está subutilizado. En este sentido, el presente estudio tuvo como objetivo analizar artículos relacionados con la enseñanza y las posibles adaptaciones de materiales en el atletismo escolar, así como los problemas y aplicaciones de este contenido. Para esto, se realizó una revisión narrativa de 25 fuentes. Con la lectura de las fuentes, los temas se dividieron en 3 categorías centrales: limitaciones y problemas en la enseñanza, posibilidades en la enseñanza del atletismo y posibles adaptaciones materiales. Finalmente, se concluyó que hay preguntas de los autores acerca de las limitaciones presentes en las escuelas, así como tratar de comprender y analizar por qué las limitaciones están presentes en el entorno escolar, sin embargo, se observó que la enseñanza del atletismo en las escuelas puede llevarse a cabo desde diferentes enfoques, además del hecho de que es posible hacer adaptaciones físicas y materiales para trabajar con pruebas de atletismo en el contexto de la educación física escolar.

Palabras ClaVe: Atletismo, Enseñanza Escolar, Educación Física.

\section{INTRODUÇÃO}

O atletismo é considerado como um esporte-base, pois sua prática corresponde aos movimentos naturais do homem, como correr, saltar e lançar (Rosa et al, 2019; Góes, Júnior \& Oliveira, 2014; Silva \& Sedorko, 2011; Constantino \& Rojo, 2020). O mesmo é composto por várias provas, sendo elas provas de pista (corridas) e provas de campo (saltos, lançamentos e arremesso) (Frainer et al, 2017; Matthiesen, 2014). O fato de a modalidade ter sua base constituída de movimentos naturais torna-a mais acessível para ser trabalhada no contexto escolar, preparando seus praticantes para os desafios cotidianos (Matthiesen, 2014).

Outro ponto é que, sendo trabalhado no âmbito escolar, favorece para um melhor desenvolvimento das habilidades motoras dos alunos (Frainer et al, 2017), possibilitando a aquisição de vivências em conjunto às demais modalidades e manifestações da cultura corporal de forma geral (Matthiesen, 2014). Contudo, a modalidade no ambiente escolar ainda é subutilizada (Silva et al, 2015; Góes, Júnior \& Oliveira, 2014; Constantino \& Rojo, 2020), sendo justificado por diversas razões, como falta de espaço e estruturas, falta de materiais adequados, formação profissional, falta de interesse dos alunos, entre outras (Silva et al, 2015; Góes, Júnior \& Oliveira, 2014; Silva \& Sedorko, 2011).

Sobre as pesquisas realizadas no atletismo, alguns estudos se dedicaram em analisar a literatura acadêmica sobre a modalidade em diferentes frentes. Frainer et al (2017), realizaram uma análise dos artigos publicados sobre o atletismo em uma visão total da modalidade. O efetivo emprego do atletismo nas aulas de Educação Física foi o tema da análise da literatura realizada por Silva et al (2015), muito próximo ao estudo realizado por Parente e Moura (2019). Por fim, as formas de se abordar temas do atletismo nas aulas de Educação Física foram investigadas a partir da literatura acadêmica, como é o caso da maratona (Matthiensen, Ginciene \& Freitas, 2012) e do arremesso de peso (Prado \& Matthiensen, 2007).

Observado que o atletismo ainda é pouco trabalhado nas aulas de Educação Física Escolar, bem como visualiza-se na literatura acadêmica uma possível fonte de formas de abordar o atletismo dentro do âmbito escolar, o presente artigo busca analisar fontes bibliográficas relacionadas ao ensino do atletismo, visando analisar as limitações do seu ensino, encontrar suas possíveis adaptações didático-pedagógicas e trazer meios de trabalhar o atletismo com materiais alternativos para as aulas práticas.

\section{MÉTodos}

A presente pesquisa se caracteriza como uma pesquisa qualitativa com caráter descritivo. Para a realização foi utilizada a revisão narrativa, que consiste em "descrever e discutir o desenvolvimento ou o estado da arte de um determinado assunto, sob o ponto de vista teórico ou contextual” (Rother, 2007, p. 1). As revisões narrativas não se comprometem a informar as fontes utilizadas, os métodos de busca e os critérios de inclusão dos manuscritos apropriados (Rother, 2007). 
Baseada nas análises da literatura publicada no formato de livros, artigos, entre outras formas de manuscritos acadêmicos, em diálogo com as análises críticas realizadas pelos autores, as revisões narrativas tem papel fundamental na educação continuada, uma vez que permite que o receptor do conteúdo apresentado no artigo acrescente e atualize o conhecimento sobre determinado assunto.

Para a realização do presente estudo, inicialmente, formulou-se as seguintes problemáticas: as aulas de atletismo estão sendo trabalhadas nas escolas? Se estão, quais as dificuldades em sua aplicação? E como se pode contribuir com o ensino do atletismo nas escolas? A partir disso, foi feita a seleção de dados por meio do Google Scholar, no qual obtive-se 43 fontes bibliográficas inicialmente (artigos em periódicos e websites, livros, entre outros) por meio da leitura dos títulos e data de publicação, que foi mantido entre 2009 e 2019.

\section{QUADRO 1}

Seleção e quantidade inicial das fontes bibliográficas, feita por análise dos títulos.

\begin{tabular}{|l|l|}
\hline FONTES BIBLIOGRÁFICAS & QUANTIDADE \\
\hline ARTIGOS EM PERIODICOS & 17 \\
\hline ARTIGOS DE WEBSITES & 9 \\
\hline LIVROS & 2 \\
\hline MONOGRAFIAS/UNIDADES DIDATICAS & 8 \\
\hline ARQUIVO DE VIDEO & 7 \\
\hline TOTAL & $\mathbf{4 3}$ \\
\hline
\end{tabular}

Fonte: elaboração própria.

Com a seleção das fontes, foi realizado a leitura dos resumos e palavras-chave como forma de manter as fontes selecionadas, e como critério de exclusão os que não estivessem relacionadas com o ensino do atletismo em escolas. A partir do terceiro procedimento, manteve-se 25 fontes para análise completa das obras. Vale ressaltar que a grande maioria das fontes excluídas são de projetos de atletismo que ocorrem no contra turno escolar, não estando vinculadas ao objetivo que envolve as aulas de atletismo durante o turno do ensino de Educação Física escolar.

QUADRO 2

Seleção final das fontes bibliográficas (entre 2009 e 2019).

\begin{tabular}{|l|l|}
\hline FONTES BIBLIOGRÁFICAS & QUANTIDADE \\
\hline ARTIGOS EM PERIODICOS & 11 \\
\hline ARTIGOS DE WEBSITES & 1 \\
\hline LIVROS & 2 \\
\hline MONOGRAFIAS/UNIDADES DIDATICAS & 4 \\
\hline ARQUIVO DE VIDEO & 7 \\
\hline TOTAL & $\mathbf{2 5}$ \\
\hline
\end{tabular}

Fonte: elaboração própria.

Apresentados os caminhos para coleta do material analisado no presente estudo, na próxima seção, apresenta-se os resultados encontrados a partir da análise das 25 fontes selecionadas, bem como sua discussão em conjunto. Para isso as abordagens são apresentadas em três momentos, os quais se constitui a partir das 
seguintes categorias centrais: Limitações e Problemáticas no Ensino, Possibilidades no Ensino do Atletismo e Possíveis Adaptações Materiais.

\section{Limitações e Problemáticas no Ensino}

Esta categoria é composta por 6 artigos que discutem a respeito das diferentes limitações que impedem/ reprimem o ensino do atletismo nas escolas (Azambuja, 2019; Dieder \& Höher, 2016; Marques \& Iora, 2009; Oliveira, Junior \& Coelho, 2010; Silva et al, 2015; Silva \& Sedorko, 2011). Os autores dos estudos de caso destacam principalmente sobre a falta de materiais e de infraestrutura como limitação do ensino, todavia destacam a necessidade da intervenção profissional do professor para a solução dessa problemática, assim como outras que serão discutidas adiante.

Os estudos apresentados discutem em comum sobre a falta de infraestrutura apontados como limitação por professores de Educação Física, sendo como uma barreira que dificulta o ensino do atletismo (Azambuja, 2019; Dieder \& Höher, 2016; Marques \& Iora, 2009; Oliveira, Junior \& Coelho, 2010; Silva et al, 2015; Silva $\&$ Sedorko, 2011). Em uma primeira perspectiva, nota-se que este é um problema presente no contexto escolar brasileiro e um dos mais apontados pelos professores de Educação Física escolar, sendo 34\% dos entrevistados por Dieder e Höher (2016), 37,5\% nos estudos de Oliveira, Junior e Coelho (2011) e 81\% no artigo de Silva e Sedorko (2011).

Outro fator apontado pelos estudos é quando o atletismo é visto, pelo professor, como esporte de alto rendimento. Essa perspectiva propicia o surgimento de uma barreira no ensino do atletismo no âmbito escolar. A maioria das escolas apenas possuem quadras polivalentes, campos e outros espaços (Damazio \& Silva, 2008) que podem ser adaptados ao ensino de atletismo. No entanto se o educador geralmente se preocupa com o ambiente específico de cada modalidade, as aulas são circunscritas ao ensino das quatro modalidades esportivas tradicionais: futebol, voleibol, handebol e basquetebol (Silva et al, 2015).

A falta de materiais oficiais do atletismo, ou seja, os implementos utilizados nas provas, é outra limitação discutida pelos autores. Nos questionários sobre limitações no ensino atletismo realizado nos estudos, a falta de materiais oficiais foi apontada por 24\% dos entrevistados por Dieder e Höher (2016), 27,4\% no artigo de Silva e Sedorko (2011) e 29,1\% nos dados de Oliveira, Junior e Coelho (2011). De fato, grande parte das escolas brasileiras não possuem materiais próprios para o ensino da modalidade, tendo em vista que apenas em escolas com projetos de atletismo no contraturno possuem materiais mais adequados e que se aproximam com os oficiais, devido ao maior investimento financeiro que recebem (Dieder \& Höher, 2016). Contudo, os materiais também são adaptáveis e de fácil confecção, podendo propiciar um ensino mais lúdico, e menos tecnicista, do objeto didático, podendo explorar diferentes possibilidades didáticas nas aulas de Educação Física (Matthiesen, 2014; Marques \& Iora, 2009).

Alguns estudos também abordam sobre a baixa experiência do educador como uma limitação no ensino do atletismo (Marques \& Iora, 2009; Silva \& Sedorko, 2011; Dieder \& Höher, 2016; Azambuja, 2019). A esse respeito, Silva e Sedorko (2011) realizaram uma pesquisa com escolas estaduais da região de Ponta GrossaPR., no qual foi analisado que as modalidades mais trabalhadas eram as corridas e os saltos, enquanto que os lançamentos, o arremesso e a marcha atlética não eram tão explorados nas aulas, concluindo com os resultados que "quanto mais técnico o gesto menos ele é abordado na escola" (Silva \& Sedorko, 2011, p. 27). Isso indica que os professores não abordam provas mais complexas do atletismo por não terem tanto domínio técnico. De certa forma, influencia diretamente no ensino, tornando-o mais básico, superficial e incompleto - devido à exclusão de provas presentes no atletismo.

Mas em relação à baixa experiência do educador, existem diversos fatores que explicam sobre essa problemática no ensino da modalidade. Marques e Iora (2009) discutem a respeito da falta de formação continuada dos educadores. Segundo os autores, a atualização de professores com cursos serviria como uma forma de inovar o ensino da modalidade, de trazer novos planos para o desenvolvimento das aulas e de 
melhorar seu contato com a modalidade. Azambuja (2019, p. 42) traz um relato de experiência com uma professora que complementa essa problemática, explicando sobre suas dificuldades no ensino:

Sou professora de Educação Física, mas a minha vivência como atleta e treinamento não abarcava o atletismo, o que dificultava bastante os treinamentos específicos. [...] tive a oportunidade de me inscrever no Curso de Técnico Nível 1 da Federação de Atletismo. Mesmo assim, ainda é um desafio constante.

Outro fator que explica sobre a baixa experiência do educador foi discutido por Dieder e Höher (2016) e, indiretamente, por Oliveira, Silva e Coelho (2010), que abordam sobre a formação dos professores durante a graduação. Durante a entrevista realizadas por Dieder e Höher (2016), as professoras voluntárias da pesquisa relataram que se sentem limitadas em relação ao conhecimento do atletismo, tornando o ensino mais simples e básico. Uma das professoras relatou sobre a experiência da mesma: "falta mais conhecimento, porque eu sei que dou um atletismo bem básico [...] Eu penso que a gente sai da faculdade muito cru, eu aprendi muita coisa ao longo dos anos, conheci alguns materiais que não tive acesso na faculdade" (Dieder \& Höher, 2016, p. 134). Os relatos destacados corroboram com a afirmação de Oliveira, Silva e Coelho (2010, p. 127), explicando que "as dificuldades apontadas pelos professores podem ser reflexos da falta de ciência decorrente talvez da formação acadêmica", conhecendo apenas o atletismo como esporte de rendimento e "não entendendo assim o atletismo adaptado, lúdico. Entendendo o atletismo como lúdico, certamente o interesse na busca de atividades seria maior".

Mesmo o ensino do atletismo estando presente na Base Nacional Comum Curricular (BNCC, 2018), Silva e Sedorko (2011) levantam a hipótese de que o seu não-ensino estaria relacionado ao comodismo e/ ou à afinidade do professor com outras modalidades mais tradicionais, como futsal, handebol e basquetebol. Contudo, Dieder e Höher (2016) explicam que a falta de motivação e de criatividade do professor são fatores que podem colaborar para a criação de uma barreira no ensino da modalidade e que influenciam no desinteresse dos docentes. Outro aspecto limitante, citado por Dieder e Höher (2016), é o tempo dedicado a Educação Física escolar, que possui poucas aulas semanais para aplicar todos os conteúdos da grade curricular, fazendo com que os professores trabalhem com o atletismo de forma superficial. Nos relatos abordados no artigo, as professoras confirmam que o calendário é relativamente curto, no qual uma delas afirma que não é possível trabalhar com o atletismo "de uma maneira profunda em 2 e 3 meses", fazendo-se necessário o recorte do conteúdo para se encaixar dentro desse período de tempo e dando apenas "uma passagem pelo conteúdo" (Dieder \& Höher, 2016, p.135).

Por fim, Dieder, Höher (2016), Oliveira, Silva e Coelho (2010) acreditam que o desinteresse dos alunos também seria uma limitação para o ensino do atletismo. É possível que esse desinteresse esteja relacionado com o pré-conceito que os alunos desenvolvem ao assimilarem o atletismo como esporte de rendimento, o que normalmente é representado pela mídia (Oliveira; Silva \& Coelho, 2010). Com isso, o discente pode considerar o atletismo como um esporte pouco atrativo e sem graça, apresentando certa resistência quando abordado pelos professores (Dieder \& Höher, 2016), tendo em vista que a questão sociocultural brasileira, onde se tem uma maior valorização do futebol, pode influenciar na escolha do aluno em praticar o futebol e reprimir a prática de outras modalidades, como o atletismo (Dieder \& Höher, 2016). Mas é possível quebrar essa barreira e atrair a atenção dos discentes para o atletismo, sendo necessário a intervenção do professor para provar que outras modalidades esportivas também proporcionam prazer e muitos benefícios (Dieder \& Höher, 2016).

\section{Possibilidades no Ensino do Atletismo}

Esta categoria é composta por 9 fontes que discutem a respeito de diferentes possibilidades de se aplicar o atletismo dentro das escolas, de modo que contribuam para um ensino mais didático aos alunos (Agápito, 2015; Domingues, 2011; Ginciene \& Matthiesen, 2017; Marques \& Iora, 2009; Matthiesen, 2014; Oliveira, 
2015; Oliveira, Junior \& Coelho, 2010; Passini \& Matthiesen, 2016; Rastelli \& Flores, 2015). Os mesmos estão separados em dois subtemas: elementos didáticos e abordagens pedagógicas.

Antes de dar sequência, é necessário frisar sobre o tripé Conteúdo, Método e Objetivo, no qual Marques e Iora (2009) afirmam haver lacunas no ensino escolar devido à falta desses aspectos fundamentais no planejamento de aula. Segundo os autores, o objetivo do professor é o primário a ser desenvolvido e também é o que direciona o mesmo na escolha das ferramentas certas - conteúdo e método - para alcançar esse objetivo com seus alunos. Portanto, os tipos de abordagens a serem apresentados a seguir são diferentes possibilidades que os professores podem estar desenvolvendo nas aulas de acordo com seus objetivos (Marques \& Iora, 2009).

\section{Elementos Didáticos}

Oliveira, Junior e Coelho (2010), assim como Agápito (2015), Domingues (2011) e Matthiesen (2014), afirmam sobre a importância da ludicidade para se trabalhar o atletismo, e as diversas modalidades de forma geral. De acordo com os autores, esse elemento faz com que a modalidade se torne mais interessante e motivadora para o público escolar, fazendo com que as diversas possibilidades de adaptaçóes materiais e físicas possam ser exploradas, assim como os próprios movimentos corporais também podem ser recriados por meio da perspectiva do lúdico.

Passini e Matthiesen (2016), Rastelli e Flores (2015) sugerem a manipulação das Tecnologias de Informação e Comunicação (TIC) como um meio didático de se dar aula. Partindo desse elemento didático, os professores podem apresentar sobre seus objetos de estudos, como por exemplo a apresentação dos padrões de movimentos no atletismo por meio de vídeos didáticos, no qual o professor consegue, por meio disso, utilizar "uma linguagem mais dinâmica e comum ao aluno, transformando e adaptando o ensino e a tradicional linguagem escrita dos livros" (Passini \& Matthiesen, 2016, p. 54).

Marques e Iora (2009), Matthiesen (2014) e Oliveira (2015) concordam sobre trabalhar com as três dimensões - Conceitual, Procedimental e Atitudinal - dentro da Educação Física escolar. Para Matthiesen (2014, p. 23), o atletismo deve ser explorado para além dos termos competitivos e tecnicistas, "abrangendo não apenas procedimentos, mas conceitos e atitudes [...] que os auxiliem a mergulhar profundamente no universo do atletismo" e que também possam auxiliar na ampliação do seu conhecimento em relação à modalidade.

\section{Abordagens Pedagógicas}

Ginciene e Matthiesen (2017) discutem sobre o Modelo Sport Education como possibilidade de ensinar diversas modalidades esportivas, inclusive o atletismo. Segundo os autores, essa abordagem permite ampliar o conhecimento a respeito da modalidade em relação às 3 dimensões da Educação Física, que são tratados e trabalhados de forma integrada. Também possibilitaria diferentes vivências aos alunos em conjunto com o esporte, desde a de praticante até a de espectador (Ginciene \& Matthiesen, 2017).

Uma das particularidades do sistema Sport Education é tornar os alunos como centro do processo de aprendizagem, "forçando-os a resolver problemas, construir seus próprios conhecimentos" e integrando sua atuação com grupos de alunos, incentivando o trabalho coletivo e a cooperatividade (Ginciene \& Matthiesen, 2017, p. 737). Outro ponto que complementa o fator anterior está na protagonização dos alunos com a resolução de problemas, no qual a condução dos mesmos em buscar suas próprias respostas são feitas por intervenção do professor, estimulando a vivência de autonomia nos estudantes.

Oliveira (2015) e Rastelli e Flores (2015) explicam sobre a abordagem Crítico-Emancipatória como meio de formar criticamente os alunos. Essa é uma abordagem que, segundo Oliveira (2015), o diálogo com os 
alunos é fundamental, no qual trabalha-se com a perspectiva de aulas abertas, ou seja, é um método que permite o aluno descobrir, compreender e expor aprendizagens através do diálogo e dos questionamentos, e também é um meio no qual o professor pode realizar provocamentos para trabalhar a reflexão e a criatividade dos estudantes (Rastelli \& Flores, 2015).

\section{Possíveis Adaptações Materiais}

Nesta categoria, estão compostos 15 fontes que ensinam como construir materiais pedagógicos alternativos para as aulas de atletismo (Capel, 2014, 2015, 2018; Cardoso, 2017; Domingues, 2011; Ginciene, 2016a, 2016b, 2016c; Martins et al, 2018; Matthiesen, 2014; Matthiesen et al, 2017; Oliveira, 2012; Petris, 2016; Sedorko \& Distefano, 2012; Silva \& Sedorko, 2011). As produções trazem formas diferentes de se produzir um mesmo objeto didático, visando o ensino lúdico do atletismo. Abordar-se-á 7 diferentes materiais de estudo: pelota, martelo, dardo, disco, bastão de revezamento, barreira para as provas de corrida e vara de salto com vara

\section{Arremesso de Peso}

Para uma possível adaptação do implemento do peso, Domingues (2011) explica sobre como utilizar a bola dente de leite e a bola de borracha como adaptação para peso. Para a sua utilização, é necessário realizar um corte pequeno na bola, com tamanho suficiente para colocar preenchimento de terra ou areia e, com a finalização, fechar o corte com fita adesiva (Domingues, 2011).

Matthiesen (2014) e Sedorko e Distefano (2012) ensinam como confeccionar o peso de sacola plástica. Para isso, amasse um papel de jornal em formato de bola que se encaixe na palma da mão, coloque-a em uma sacola plástica, acrescente areia ou terra para torná-lo mais pesado e, na finalização, amarre ou feche a sacola com uma fita adesiva, cortando o excesso. É possível utilizar meias para envolver a bola, sendo preciso amarrar e cortar o excesso.

Por fim, uma alternativa de fácil acesso seria utilizar bolas de não confecção para adaptar no arremesso de peso, sendo possível a utilização de bolas esportivas. Autores como Matthiesen et al (2017) e Domingues (2011) mencionam sobre o uso de medicine balls e bolas de vôlei, porém as bolas de futebol, bolas de tênis, entre outros materiais semelhantes, são objetos plausíveis para o ensino do arremesso de peso.

\section{Lançamento de Martelo}

Assim como os procedimentos de adaptação para peso, Domingues (2011) explica sobre como utilizar a bola dente de leite como adaptação para martelo. Para isso é necessário realizar um corte pequeno na bola para colocar preenchimento de terra ou areia e, com a finalização, fechá-lo com fita adesiva. Contudo, deverá prendê-lo com um arame, deixando suas duas pontas e enrolando os cabos um no outro formando apenas um cabo. Segundo Domingues (2011), o comprimento precisa alcançar a altura da cintura dos alunos, variando em relação ao público que será trabalhado. No acabamento final do cabo, deverá ser feito uma argola triangular com o arame para a empunhadura, encapando-a com um papelão que será fixado por fita adesiva.

Matthiesen (2014) e Sedorko e Distefano (2012) ensinam como confeccionar o martelo de sacola plástica. Para o implemento, é preciso amassar papel de jornal em formato de bola que se encaixe na palma da mão, coloca-la em uma sacola plástica, acrescentar areia ou terra para torna-lo mais pesado e fechá-la com uma fita adesiva. Segundo os autores, o cabo pode ser feito com meia de nylon trançada ou alguns tipos de cordas, no qual a empunhadura será feita em formato de triângulo utilizando um pedaço de borracha ou um rolo de durex usado (Matthiesen, 2014; Sedorko \& Distefano, 2012). 
Outra maneira de confeccionar o martelo é utilizando meias como material. Segundo Matthiesen (2014), os procedimentos realizados com martelo e sacola plástica se mantem nessa confecção, mudando apenas a matéria prima. Entretanto, na sugestão de Capel (2014), são acrescentados a abraçadeira de nylon, uma bolsa com seis argolas e um tubo de alumínio para empunhadura. O procedimento inicia-se passando uma corda por dentro das argolas da bolsa e prendendo-a com a abraçadeira de nylon. $\mathrm{Na}$ outra extremidade da corda, o tubo de alumínio serve de empunhadura na alça do martelo, sendo novamente a corda presa com a abraçadeira. Em sequência, a bola de peso com areia, envolvida por saco plástico e meia deve ser inserida na bolsa.

Matthiesen e colaboradores (2017) mencionam sobre montar o martelo com meia calça de nylon/seda. Para a confecção, são necessários um saco plástico, areia, bexigas e meia calça. De início, coloca-se areia (úmida) em um saco plástico, amarrando e revestindo o saco com bexigas para reforçar o acabamento do peso. O peso confeccionado deve ser inserido na meia calça, dando um nó reforçado próximo da bola e fixado com fita adesiva. Uma parte da meia será trançada e costurada, enquanto que a sobra das duas pernas será presa por um nó, formando a empunhadura do martelo. Os mesmos autores mencionam sobre utilizar meias de cano longo no lugar da meia calça, mantendo-se os demais procedimentos (Matthiensen et al, 2017).

Alguns autores não fazem menção ao comprimento do cabo do martelo, nem ao peso da bola, sendo de dever do professor responsável a adaptação do implemento ao público. Domingues (2011) recomenda que o comprimento do cabo alcance a altura da cintura, enquanto que no vídeo publicado por Capel (2014) fica subentendido que o comprimento do cabo ultrapassa a altura da cintura.

Por fim, assim como na sugestão no arremesso de peso, é possível a utilização de bolas prontas para adaptar na modalidade, como as medicine balls, bolas de vôlei, bolas de futebol, entre outros. Entretanto, se faz necessário a confecção ou adaptação do cabo para a sua combinação com a bola, como no exemplo do martelo de Capel (2014), no qual o mesmo montou uma bolsa de tecido resistente para inserir e retirar as bolas, em conjunto com uma corda e um tubo de alumínio.

\section{Lançamento de Dardo}

Para adaptar o implemento utilizado na prova do lançamento do dardo, Domingues (2011) e Oliveira (2012) sugerem a confecção do dardo de bambu como material alternativo. As medidas do dardo devem estar entre 60 e $150 \mathrm{~cm}$, o que dependerá principalmente do público que será trabalhado, sendo que em uma das extremidades, deve ser pintado para representar a ponta do dardo. Algo alternativo para se fazer na ponta, ao invés de pintá-la, é possível colocar uma bola de tênis fixa nessa extremidade, no qual fará com que a ponta do dardo encoste primeiro na superfície quando lançada (Ginciene, 2016c). No local da empunhadura, é preciso utilizar barbante e fita durex para delimitar o manuseamento do dardo, contudo se faz necessário encontrar o ponto de equilíbrio da vara de bambu para enrolar o barbante, equilibrando-a na palma da mão (Domingues, 2011).

A madeira utilizada como cabo de vassoura, é outro material alternativo para a adaptação do dardo (Domingues, 2011; Silva \& Sedorko, 2011, Oliveira, 2012; Sedorko \& Distefano, 2012, Cardoso, 2017). Assim como o dardo de bambu, é necessário uma medida entre 60 e $150 \mathrm{~cm}$, com uma das extremidades representando a ponta da lança - podendo ser uma bola de tênis fixa no cabo, uma tinta, entre outras possibilidades - , sendo que a empunhadura pode ser feita com barbante ou cartolina, que são fixos com fita ou cola, ou até mesmo a tinta para representar o ponto de manuseio. Algo que pode ser acrescentado é colocar uma garrafa PET recortada na extremidade oposta ao da ponta do dardo, que será importante na iniciação esportiva devido ao melhor direcionamento do dardo quando lançado. A parte da garrafa que será utilizada é a porção superior (ombro), sendo preciso dobrá-lo de forma que, visto inferiormente, se assemelhe a um quadrado curvo (Cardoso, 2017). Em seguida, prenda a garrafa cortada na extremidade do cabo com fita ou cola. 
Para Ginciene (2016c) e Matthiesen e colaboradores (2017) o material plástico de PVC também é uma opção para adaptar o implemento para se trabalhar com a modalidade. Para isso, recomenda-se utilizar um cano com comprimento entre 100 e $150 \mathrm{~cm}$, uma bola de tênis, um barbante e um estilete. A bola precisa ter um corte que se encaixe com a extremidade do cano para aumentar o peso da ponta, então com o estilete, a bola será cortada linearmente (Ginciene, 2016c).

Por fim, Capel (2015) ensina como construir um dardo de espuma. Para a confecção do implemento adaptado, é necessário um flutuador de espuma do tipo espaguete, com comprimento entre 60 e $80 \mathrm{~cm}$, bola de tênis, tecidos de TNT, uma abraçadeira de nylon e fita adesiva. A bola de tênis deve ser fixada em uma das extremidades da espuma com um dos tecidos de TNT, no qual o mesmo será preso com a abraçadeira de nylon e a fita adesiva. Na extremidade oposta, o segundo tecido de TNT, já cortado em tiras, deve ser fixado com fita adesiva (Capel, 2015).

\section{Lançamento de Disco}

O disco utilizado nos lançamentos também é passível de adaptações para a utilização no processo pedagógico do ensino do atletismo. Domingues (2011), Oliveira (2012) e Sedorko e Distefano (2012), sugerem produzir um disco utilizando o material papelão. Para o mesmo ser feito, são necessários dois círculos de papelão, de diâmetro entre 22 e $30 \mathrm{~cm}$, com preenchimento de papeis, jornais, cerâmicas, entre outros. Este é envolvido nas partes superior e inferior, e envolvidos a circunferência do disco. Já Martins (2018) e Matthiesen (2014) explicam em comum sobre como montar um disco de prato, que possui um procedimento semelhante ao anterior, contudo, são utilizados pratos de plástico como material intermediário.

Oliveira (2012) também traz outras referências e procedimentos de como trabalhar com diferentes adaptações do disco. São elas as adaptações feitas a partir de materiais como tampa de panela, discos de madeira, bambolê - oficialmente conhecidos como arcos na ginástica-, por fim, o disco com pneu de bicicleta.

\section{Bastões de Revezamento}

As corridas de revezamento também precisam da utilização de um implemento, da mesma forma dos demais o bastão é passível de adaptações. Petris (2016) ensina sobre a confecção do bastão, o qual pode ser confeccionado com madeira, metal ou outros tipos de materiais que sejam rígidos, sendo estes cilíndricos, ocos, entre 28 e $30 \mathrm{~cm}$ de comprimento e de 12 a $13 \mathrm{~cm}$ de circunferência, pesando 50 g ou menos. É necessário frisar que as medidas sugeridas por Petris (2016), assim como os materiais, são mais próximos à modalidade oficial de corrida de revezamento, contudo quando envolve-se adaptação para determinado público, pode haver alterações nas medidas para a melhor adequação ao público alvo, tendo em vista que o objetivo do professor em aplicar a modalidade e a disponibilidade de materiais também podem influenciar na confecção do implemento.

Nesse sentido, observa-se que Sedorko e Distefano (2012), Silva e Sedorko (2011) e Domingues (2011), sugerem o uso de madeiras utilizadas em cabo de vassoura para isso. Matthiesen (2014) indica a possibilidade de adaptar com PVC e gravetos. Já Ginciene (2016b) e Matthiesen (2014) ensinam como confeccionar o bastão com folhas de jornal e fita adesiva, em que é preciso enrolar o material até uma forma cilíndrica, que será enrolado novamente em outra folha de jornal, certificando-se que o bastão esteja firme. Os autores não mencionam sobre enfeitar o material, todavia é possível utilizar materiais como folhas EVA coloridas, ou tecidos TNT para tornar o objeto mais didático para a turma que será aplicada. 


\section{Barreiras de Corrida}

Ainda nas provas de corridas, as barreiras são materiais de difícil aquisição do material oficial, e também são possíveis de adaptação para os usos pedagógicos. Matthiesen (2014) cita sobre confeccionar barreiras com garrafas pet. A primeira sugestão é de utilizar duas garrafas tipo pet, com o preenchimento de terra ou areia, e um barbante fixada abaixo da tampa, com medida de pelo menos $50 \mathrm{~cm}$ de comprimento. A mesma autora cita sobre utilizar cabos de vassoura ou folha de jornal dupla enroladas no lugar do barbante (Matthiesen, 2014). Outra possibilidade é utilizar recipientes de armazenamento de tinta. Para isso é necessário latas com volume entre 10 e 50 litros e, sobre o suporte, um cabo de vassoura fixado sobre as latas. É possível utilizar outros materiais que substituem o cabo de vassoura, como barbante, canos de PVC, entre outros.

Matthiesen (2014), Domingues (2011) e Sedorko e Distefano (2012) ensinam como confeccionar barreiras com caixa de papelão. Assim como no exemplo anterior, Matthiesen (2014) sugere o posicionamento do cabo de vassoura sobre os suportes, sendo no caso caixas de papelão. Umas variações do suporte seria colocar as caixas invertidas e lado a lado no chão como obstáculo (Matthiesen, 2014; Domingues, 2011; Sedorko \& Distefano, 2012). Além dos já sugeridos, também é possível adaptar com a utilização de tubulação em PVC (Matthiesen, 2014; Matthiesen et al, 2017; Ginciene, 2016a).

\section{Salto com Vara}

Em relação à vara da modalidade Salto com Vara, existem poucas referências abordando e explicando sobre a adaptação do mesmo, tendo em vista também que são poucos os materiais adaptáveis à sua prática, contudo é possível (e se faz necessário) trabalhar com a modalidade no âmbito escolar. Ao todo, dois materiais foram citados: bambu e cabo de vassoura. Matthiesen (2014) e Domingues (2011) fazem referência à produção da vara de bambu. Os autores recomendam que a vara tenha comprimento de aproximadamente $2 \mathrm{~m}$, contudo é possível trabalhar com medidas menores, dependendo do público que será trabalhado.

Em sequência, a vara confeccionada com cabo de vassoura é citada por Matthiesen (2014)e, indiretamente, por Capel (2018). Assim como a vara de bambu, a medida pode atingir dois metros ou menos. Algo que pode ser acrescentado é colocar uma bola de tênis bem fixada na extremidade de apoio (extremidade que toca na superfície) para facilitar na movimentação da vara quando em contato com a superfície, assim como pintar o material com tinta para deixa-lo mais didático (Capel, 2018).

\section{CONSIDERAÇÕES FINAIS}

Por meio de uma síntese realizada nos vários referenciais teóricos, pode-se observar a inquietude dos pesquisadores em questionar sobre as limitações para se trabalhar com o atletismo nas escolas, assim como procuram entender e analisar porque as limitações se fazem presentes nesse contexto. Embora atualmente haja várias limitações dificultando o ensino do atletismo nas escolas, sendo que as principais são a falta de infraestrutura e de materiais, percebe-se também a preocupação por parte dos pesquisadores em resgatar a modalidade, oferecendo sua prática por meio de planejamentos e de diferentes abordagens didáticopedagógicas no ensino que podem ser executadas pelos professores, visando auxiliá-los a quebrar essa barreira de limitações que se faz presente no âmbito escolar.

Conclui-se que em relação as limitações e problemáticas no ensino do atletismo, as fontes apresentam questionamentos sobre essas limitações presentes nas escolas, assim como procuram entender e analisar porque as limitações se fazem presentes no âmbito escolar. Porém, os autores deixam claro que são a criatividade do professor, assim como sua experiência e interesse, que determinam se o atletismo será ou não trabalhado no âmbito escolar. 
Já em relação as possibilidades no ensino do atletismo, conclui-se que, com os diferentes elementos didáticos e as diferentes abordagens pedagógicas levantadas pela literatura analisada, é possível trabalhar com o atletismo de diferentes modos além do tradicional modo tecnicista que se mantém em escolas. Essas diferentes abordagens têm como objetivos auxiliar o professor a formar um cidadão crítico e reflexivo, tendo em vista que a disciplina de Educação Física se apresenta como meio para essa finalidade.

Quando se refere as possíveis adaptações, conclui-se que mesmo que haja muitas barreiras e elementos que distanciam o atletismo do ambiente escolar, existem diversas variações criativas para se montar materiais como objeto didático do atletismo, e assim implementar o seu conteúdo na Educação Física escolar. Sendo que a produção dos mesmos pode ser executada pelos próprios professores para as práticas de atletismo, ou até mesmo por grupos de alunos com a orientação e ajuda do professor, visando um maior contato dos estudantes com o material de ensino.

Por fim, acredita-se que esse estudo, apoiado em uma literatura acadêmica especializada nos estudos do atletismo escolar, no formato de uma revisão narrativa, pode ser um mecanismo de capacitação dos professores que atuam com a modalidade no ambiente escolar, trazendo em suas páginas limitações, diferentes abordagens e também possíveis adaptações para trabalhar o atletismo dentro da escola.

\section{REFERÊNCIAS:}

Agápito, C. M. (2015) O atletismo como alternativa metodológica nas aulas de educação física (Trabalho de conclusão de curso). Faculdade de Educação e Meio Ambiente - FAEMA, Ariquemes, RO, Brasil.

Azambuja, V. A. (2019). Atletismo em Coronel Vivida: participação, dificuldades e resultados. Ciência éminha praia, 6(1), 39-44.

Capel, T. (2014, setembro 2). Atletismo escolar construção de material para lançamento do martelo. [Arquivo de vídeo]. Recuperado de: https://youtu.be/qCkoScB4qDA

Capel, T. (2015, junho 6). Atletismo Construção de dardo adaptado para crianças. [Arquivo de vídeo]. Recuperado de: https://youtu.be/r0akGCk_i2k

Capel, T. (2018, novembro 9). Pedagogia do salto com vara. [Arquivo de vídeo]. Recuperado de: https://youtu.be/T LW4MMQTc5w

Cardoso, E. (2017, setembro 1). Confeç̧ão dardo atletismo. [Arquivo de vídeo]. Recuperado de: https://youtu.be/b CVvVrTrt9I

Constantino, A. S., \& Rojo, J. (2020). El atletismo escolar desde la perspectiva de los estudiantes de educación física. Revista Universitaria De La Educación Física Y El Deporte, (13), 39-53. https://doi.org/10.28997/ruefd.v0i13.5

Damazio, M. S., \& Silva, M. F. P. (2008). O ensino da educação física e o espaço físico em questão. Pensar a prática, 11(2), 189-196.

Dieder, J. A., \& Höher, A. J. (2016). O atletismo nas aulas de Educação Física das escolas de Novo Hamburgo/RS: possibilidades e limitações. Nuances: estudos sobre Educação, 27(1), 127-146.

Domingues, R. (2011). Explorando o lúdico nas aulas de educação física. Secretaria de Estado da Educação, Unidade Didática, v. 2, Universidade Estadual do Norte do Paraná, Jacarezinho.

Frainer, D. E. S., Abad, C. C. C., De-Oliveira, F. R., \& Pazin, J. (2017). Análise da produção científica sobre atletismo no Brasil: uma revisão sistemática. Revista brasileira de ciência e movimento, 25(1), 199-211.

Ginciene, G. (2016a, janeiro 28) Como fazer um implemento adaptado: Barreira. [Arquivo de vídeo]. Recuperado de: https://youtu.be/ZOk3S_EsoeU

Ginciene, G. (2016b, fevereiro 16) Como fazer um implemento adaptado: Bastão de Revezamento. [Arquivo de vídeo]. Recuperado de: https://youtu.be/v46CQYB6qPY

Ginciene, G. (2016c, fevereiro 16). Como fazer um implemento adaptado: Dardo. [Arquivo de vídeo]. Recuperado de: https://youtu.be/nRvCSN7VHfI 
Ginciene, G., \& Matthiesen, S. Q. (2017). O modelo do Sport Education no ensino do atletismo na escola. Movimento (ESEFID/UFRGS), 23(2), 729-742.

Góes, F. T., Júnior, P. R. V., \& Oliveira, P. A. S. (2014). Algumas reflexões sobre a inserção e o ensino do atletismo na educação física escolar. Revista mackenzie de educação física e esporte, 13(1), 96-108.

Marques, C. L., \& Iora, J. A. (2009). Atletismo escolar: possibilidades e estratégias de objetivo, conteúdo e método em aulas de educação física. Movimento (ESEFID/UFRGS), 15(2), 103-118.

Martins, A. S., Schardong, Í., Rios, K. R., Lemos, L. F. C., Junior, N. R., \& de Melo, R. C. (2019). Construção do material didático em sala de aula: uma proposta para o lançamento do disco envolvendo as mídias. Stephani, A. D. (Org.) Educação: uma nova agenda para a emancipação (pp. 147-150). Ponta Grossa, PR: Atena Editora.

Matthiesen, S. Q. (2014). Atletismo na escola. Maringá: Eduem.

Matthiesen, S. Q., Faganello-Gemente, F. R., Ginciene, G., Mota, E. V., da Silva, T. P. F., \& Guimarães, V. D. (2017). Sobre materiais alternativos para o ensino do atletismo. Cadernos de Formação RBCE, 8(2), 45-58.

Matthiesen, S. Q., Ginciene, G., \& Freitas, F. P. R. D. (2012). Registros da maratona em Jogos Olímpicos para a difusão em aulas de Educação Física. Revista Brasileira de Educação Física e Esporte, 26(3), 463-471.

Ministério da Educação (2018). Base Nacional Comum Curricular. Brasília. Disponível em: http://basenacionalcom um.mec.gov.br/a-base.

Mota, E. V., Gemente, F. R. F., Ginciene, G., Daniel, J. C., \& Matthiesen, S. Q. (2015). Atletismo (ainda) não se aprende na escola? Revisitando artigos publicados em periódicos científicos da Educação Física nos últimos anos. Movimento, 21(4), 1111-1122.

Oliveira, F. S. D. (2015). Construção de materiais pedagógicos nas aulas de educação física escolar para o ensino fundamental com o conteúdo atletismo (Trabalho de conclusão de curso). Universidade Federal do Rio Grande do Norte - UFRN, Natal, RN, Brasil.

Oliveira, H. L. A. (2012). Metodologia de ensino de educação fisica: arremesso de dardo e disco. Secretaria de Estado da Educação, Caderno Temático, v. 2, Unicentro, Guarapuava.

Oliveira, R. B., Junior, D. B. R., \& Coelho, E. F. (2016). O desenvolvimento do atletismo nas aulas de Educação Física das escolas de Muriaé (MG). Revista Cientifica da Faminas, 6(3), 115-131.

Parente, M. L. C., \& Moura, D. L. (2019). Ensino do atletismo na Educação Física escolar: uma revisão sistemática qualitativa na produção brasileira e internacional. Arquivos em Movimento, 15(1), 256-271.

Passini, G. K., \& Matthiesen, S. Q. (2017). Sobre a produção de material didático para o ensino do atletismo na escola com auxílio das tecnologias da informação e comunicação. Arquivos em Movimento, 12(2), 52-63.

Petris, B. C. (2016). Teoria e prática do atletismo (1ª ed.). Rio de Janeiro: SESES.

Prado, V. M., \& Matthiesen, S. Q. (2007). Para além dos procedimentos técnicos: o atletismo em aulas de Educação Física. Motriz. Journal of Physical Education. UNESP, 120-127.

Rastelli, G., \& Flores, M. V. (2016). O atletismo nas aulas de educação física infantil: relato de experiência no estágio supervisionado I. Cadernos de Formação RBCE, 6(2), 69-76.

Rosa, R. S., Mendes, F. G., Backes, A. F., Ramos, V., \& de Souza, E. R. (2019). Atletismo e escola: interfaces com o conhecimento e desenvolvimento humano discente. EducaciónFísica y Ciencia, 21(3), e090.

Rother, E. T. (2007). Revisão sistemática X revisão narrativa. Acta Paulista de Enfermagem, 20(2), v-vi.

Sedorko, C. M. \& Distefano, F. (2012). O atletismo no contexto escolar: possibilidades didáticas no $2^{\circ}$ ciclo do ensino fundamental. EFDeportes.com, Revista Digital. Buenos Aires, Ano 16, $N^{\circ} 165$.

Silva, A. I., \& Sedorko, C. M. (2011). Atletismo como conteúdo das aulas de educação física em escolas estaduais do município de Ponta Grossa. Teoria e Prática da Educação, 14(3), 25-33. 